\title{
Study on Energy Efficiency Evaluation System of 3E\&D
}

\author{
He Xin ${ }^{*}$ and Zhihui Zhang
}

\author{
School of Economics \& Management, Beijing Institute of Petrochemical Technology, Beijing 102617, China
}

\begin{abstract}
This paper elaborates the mutual relation of energy, economy, environment and sustainable development, analyzes the key factors affecting energy efficiency. By determining the goal and connotation of energy efficiency, this paper establishes the evaluation model of energy efficiency, and constructs the energy utilization efficiency evaluation system of energy supply, economic growth, environmentally friendly and sustainable development (3E\&D). This index system not only can be applied to the evaluation of energy efficiency and the forecast of energy consumption, but also can be used for guiding energy saving and emission reduction, and it has wide applicability.
\end{abstract}

Keywords: 3E\&D, energy efficiency, evaluation method, index system.

\section{INTRODUCTION}

The so-called "Energy Efficiency Comprehensive Evaluation" is to assess the comprehensive energy consumption efficiency of production or social activity of enterprise or region over a period of time, and it is also known as comprehensive energy consumption efficiency evaluation. In this paper, it is abbreviated as "energy consumption evaluation" or "energy efficiency evaluation". Its purpose is to explore the condition of the overall energy utilization efficiency of country, region or enterprise, and provide theoretical basis for economic development, industrial restructuring and environmental protection. Accordingly, it will facilitate the promotion of energy efficiency to maintain the solid and sustainable development of social economy [1].

\section{RESEARCH STATUS}

Concentrating on the problem of greenhouse gas reduction, the western developed countries employ different methods to develop a series of commercialized general energy efficiency evaluation and optimization models. Methodologically, these models can be generalized into two kinds of model techniques, i.e. "Bottom Up" and "Top Down".

The Bottom Up model researches the combined effect caused by micro change of technical economy of bottom leyel of unit and its financial effect. In this kind of models, MARKAL, ESOM and others in the energy field are the earliest. The biggest problem existing in these pure technology models is that the model does not take economic system into account, and various involved economic variables need to be given exogenously. Moreover, the calculation based on this technical model cannot provide definite policy proposal to the policy maker. Consequently, on the basis of existing technical model, the researchers conduct modification. In this field, the most famous works include ETA-MACRO model (also known as GLOBAL 2100 model) and MARKAL-MACRO model (Germany, America). For both models, the macro economic growth optimization model MACRO module is added on the basis of existing technical model [2-4]. However, although they can bring the economic system into the model analysis, the way of considering economic system is very rough and macroscopic.

The Top-Down model researches the relation between macro economic change and energy system supply and demand, from the impact of economic development on departments, and with energy price, economic elasticity as leading economic indicators. This kind of models apply to the research of macro-economic analysis and energy policy planning, and the commonly-used models include HudsonJorgenson model (1974), which uses the macroscopic measurement economic model for energy system analysis for the first time; MEGABARE model (Australian Economic Administration of Agriculture and Resource), which is a dynamic CGE model; SGM model (America), which is an I/O model, etc. [5-9]. These models better describe the mutual effect between national economic sectors, and resource and economy. However, the dependence on macro economic data is strong, and the result is ambiguous, lacking of operability.

Based on the insight to the above two models, people get to know that if the two models can be combined to form a comprehensive evaluation model in the field of energy economy - environment, it can meet the need of environmental policy analysis and the demand of energy planning. The famous combined models include HERMESMIDAS model (Carpos, 1989), MENSA-MERG model (Australia, 1986), LEAP model (Boston Tellus Research Institution, 1982), etc. [10].

In recent years, concentrating on the problem of greenhouse gases emission limit, a series of models have been developed in China, such as Chinese Markal- Macro 


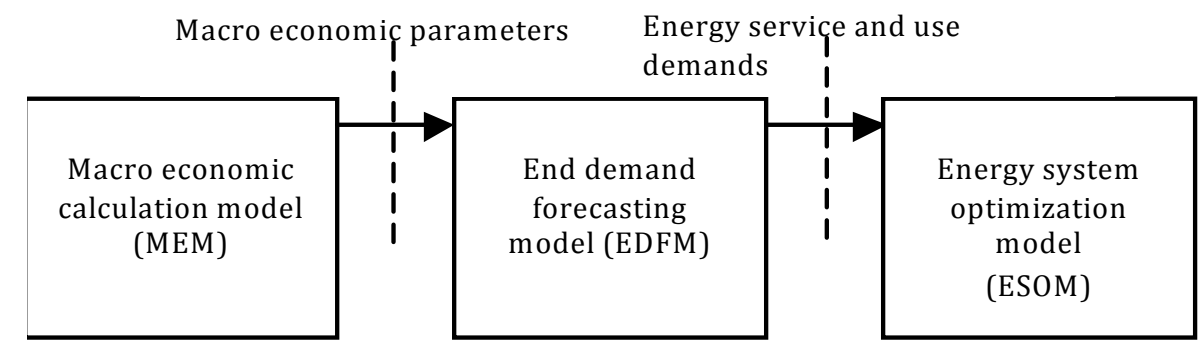

Fig. (1). 3E model block.

model, greenhouse gas reduction IO model, INET energy system model, system dynamics model (Chinese Academy of Social Sciences), Chinese CGE model (Chinese Academy of Social Sciences), DRCCGE (Development Research Center of the State Council), IPAC (NDRC Energy Research Institute), 3E model (Research Laboratory of Energy System Planning of Nuclear Research Institute of Tsinghua University), etc. Of which, 3E model block diagram is as shown in Fig. (1) [11-15].

The model shown in Fig. (1) includes three subsystems, i.e. energy, economy and environment, with certain superiority, but some problems or defects still exist.

(1) The feedback of energy system on economic development has not been considered yet. At present, the research is conducted only under the condition that the final demand remains unchanged. As shown in Fig. (2) (the part marked with imaginary line remains to be completed), the model lacks of persuasion because it does not consider the mutual effect between energy system and economic system and the cost of greenhouse gas reduction.

(2) The existing economic model of $3 \mathrm{E}$ model is a macroeconometric model. On forecasting the economic trend, it is calculated year by year, starting from base year. Except few exogenous variables which need to be input manually, all endogenous variables are calculated from the model.

(3) In fact, the $3 \mathrm{E}$ model is only an economy - energy system, not a comprehensive evaluation model which can really cover economy - energy - environment system. The impact of environment on economic system is reflected only from the cost of greenhouse gas reduction, lacking of a set of evaluation module for sustainable development index.

(4) At present, the $\mathrm{CO}^{2}$ emission reduction still concentrates on the cost of emission reduction. Although the model researches the $\mathrm{CO}^{2}$ emission

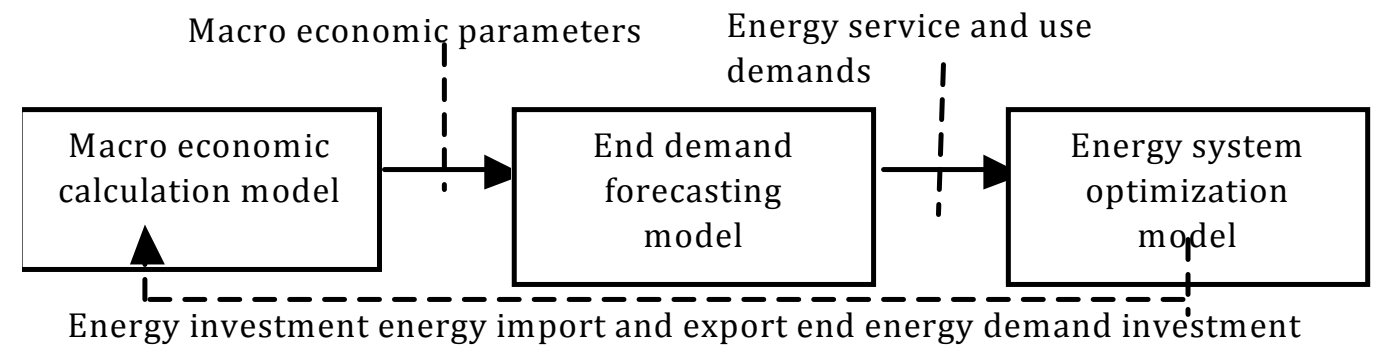

reduction cost of industry, service, transportation, lives of residents, electric power sector, if we want to make the $\mathrm{CO}^{2}$ reduction research more pertinent, it is necessary to conduct detailed economic impact analysis to industry, only in this way, it can play the role of policy proposal.

For this purpose, we need to research a comprehensive energy efficiency evaluation method suited to region or enterprise energy-saving optimization, and build its model.

\section{EVALUATION CONTENT}

Evaluation index system should meet the principles such as systematicness, simplicity, operability and reliability, etc, practically embody essential characteristic of low energy consumption and high utilization rate, and conduct comprehensive evaluation to energy efficiency from four aspects, i.e. energy, output, environment and sustainability. In order to increase the hierarchy, the evaluation system is divided into 4 levels, namely A, B, C, and D. In order to embody the openness of evaluation system, Level D index can be set according to different evaluation objects, such as administrative region, industry, enterprise, etc.

In the first place, energy efficiency evaluation needs to consider the matching degree of energy consumption structure and supply and the processing conversion rate of energy products, namely the evaluation on energy system. Secondly, the purpose of energy consumption is to guarantee the stable development of region, industry or enterprise, hence it is necessary to assess the efficiency of energy input and output of energy consumption. In addition, the energy consumption accompanies environmental damage, thus it is necessary to assess the environmental impact of energy consumption under the condition of carbon emission constraint. Based on the key function of energy in society, economy, environment and sustainability, the content of energy efficiency evaluation can be decomposed into efficiency evaluation of four subsystems, namely energy, 
output, environment and sustainability. For the evaluation content of 3E subsystem, we can refer to relevant literatures. Here, we emphasize to analyze the evaluation of sustainability $[16,17]$.

Energy consumption is the basic guarantee of social economic activity, and the energy utilization efficiency is crucial to the sustainable development of social economy. Specifically, the evaluation of energy utilization efficiency in the view of sustainable development of social economy should contain the following aspects:

(1) Safety: meet the rational need of region or enterprise development to the energy, support the sustainable development of economic society, and guarantee the stability of energy system to be able to effectively prevent, cope with and control systematic risk.

(2) Environmental sustainability: the energy system should develop towards low cost and high efficiency, and the pollution problem caused by energy activity is improved continuously and within the controllable range.

(3) Safeguard measures: develop advanced energy-saving technological means and economic means, combine the practical situation of region or enterprise, put forward feasible scheme and provide policy support and capital inclination. Through a series of technical transformation, energy saving policies and regulations and industrial restructuring, make the energy technology effectively support the high level development of region or enterprise for a long time, and provide support to the development and utilization of energy system.

On the basis of explaining the sustainable development in terms of energy, the general condition of sustainable development presented in this paper should be measured from three aspects. The first is safety index, i.e. the degree of dependence of region or enterprise on energy supply; the second is low carbon index, i.e. the proportion of clean energy in total energy consumption; the third is policy input level, i.e. the introduction intensity and capital input of region or enterprise energy policy, energy saving technology and energy saving new product related to energy consumption, etc.

\section{SYSTEM STRUCTURE}

The energy efficiency evaluation index is divided into four levels, namely A, B, C, and D. Of which, Level A is overall index, i.e. general goal. The larger the value of $A$, the higher the comprehensive energy utilization efficiency of evaluation object. Level B is divided into four indexes, i.e. energy subsystem (Energy system), output subsystem (Economic system), environment subsystem (Environment system) and sustainable development subsystem (Development system). The four indexes are distinguished from each other and correlated with each other. The goals of four subsystems are respectively energy supply, economic growth, environmentally friendly and sustainable development, namely 3E\&D for short. Each subsystem consists of its corresponding impact factors, denoted by
Level C. The larger the evaluation value, the higher the corresponding energy consumption efficiency. In a same Level C index, it corresponds to associated Level D index. For the convenience of narration, ordinal number I to IV is taken for the subscript i. $\mathrm{Ai}, \mathrm{Bi}, \mathrm{Ci}$, and $\mathrm{Di}$ mark four subsystems four levels in order, respectively described as follows:

\subsection{Energy Subsystem}

Goal: mainly assess the energy production efficiency of evaluation object.

Connotation: assess the energy production efficiency and energy consumption structure.

This subsystem can be decomposed into two levels. The first level consists of energy technical efficiency and energy consumption structure, denoted by $\mathrm{C}_{\mathrm{I}, 1}$ and $\mathrm{C}_{\mathrm{I}, 2}$ in order. The second level is the specific content or manifestation form of its previous level, denoted by $\mathrm{D}_{\mathrm{I}}$. The third level is the source of basic information of corresponding index of previous level, and it is the bottom level of the comprehensive evaluation index system, denoted by $\mathrm{E}_{\mathrm{I}}$. These indexes can be obtained from certain data through simple conversion, but they do not involve in system evaluation.

\subsection{Output Subsystem}

Goal: the impact of energy consumption on region or enterprise economic activity.

Connotation: measure the contribution of region or enterprise energy consumption to social economic activity, namely the energy intensity and industry or product structure of evaluation object.

The output subsystem evaluation index of energy efficiency consists of benefit index $\mathrm{C}_{\mathrm{II}, 1}$, elasticity index $\mathrm{C}_{\mathrm{II}}$, 2, structure index $\mathrm{C}_{\mathrm{II}}, 3$ and non-production energy consumption index $\mathrm{C}_{\mathrm{II}, 4}$ of energy consumption output rate.

In terms of energy consumption economic efficiency, the aggregate index $\mathrm{C}_{\mathrm{II}, 1}$ defines the economic growth value of region or enterprise unit energy consumption, which is the ratio of gross economic output and overall energy consumption, namely the output of unit energy consumption.

The energy consumption elasticity actually describes the contribution of economic growth rate to energy consumption growth rate. According to the principle of positive index, the elasticity index $\mathrm{C}_{\mathrm{II}}, 2$ of energy consumption economic efficiency should be defined as economic growth rate of unit energy consumption growth rate, namely the energy consumption elasticity of output.

The structure index $\mathrm{C}_{\mathrm{II}, 3}$ of energy consumption mainly refers to region industrial structure or enterprise product structure.

Non-production energy consumption index $\mathrm{C}_{\mathrm{II}, 4}$ is the energy consumption index related to enterprise nonproduction link, which can be described with region per capita residential energy consumption or enterprise nonproduction link energy consumption index. 


\subsection{Environment Subsystem}

Goal: the impact of energy consumption to environment.

Connotation: assess the impact of emission of energy consumption to region atmosphere, water resource and dwelling environment.

The emission of industrial effluents, waste gas and solid waste forms the environmental pollution of industrial production, which can be classified into energy and nonenergy product production emission, and the latter can also be classified into the emission of energy consumption and the emission of non-energy consumption. As the subsystem of energy consumption efficiency evaluation, this index should emphasize the environmental pollution factors related to energy production and consumption, and the corresponding structure index consists of pollutant reduction index $\mathrm{C}_{\mathrm{III}}, 1$, cycle index $\mathrm{C}_{\mathrm{III}, 2}$ and emission index $\mathrm{C}_{\mathrm{III}}, 3$.

Energy consumption is the necessary factor for supporting the region economic development, but its accompanied $\mathrm{CO}^{2}$ emission only causes air pollution, hence the pollutant reduction index $\mathrm{C}_{\mathrm{III}, 1}$ can consist of unit energy consumption $\mathrm{CO}^{2}$ emission, removal rate of industrial sulfur dioxide and removal rate of industrial fumes, and other Level $\mathrm{D}$ indexes. The cycle index $\mathrm{C}_{\mathrm{III}}, 2$ can consist of resource circulation utilization rate and industrial waste comprehensive utilization rate. The emission index $\mathrm{C}_{\mathrm{III}, 3}$ can be described with region per capita energy consumption $\mathrm{CO}^{2}$ emission, enterprise unit product $\mathrm{CO}^{2}$ emission, etc.

\subsection{Sustainability Subsystem}

Goal: the impact of energy consumption on sustainable development.

Connotation: the sustainability of energy supply and consumption mainly includes energy safety, low emission energy consumption capacity and new energy development situation, etc. The sustainability of energy consumption is the basic guarantee of the sustainable development of social economy, and the sustainability of energy supply is the foundation of sustainable consumption of energy. Therefore, the sustainability is the important content of energy consumption efficiency evaluation.

In view of existing energy utilization technology, the primary content of energy consumption sustainability is the safety of energy supply and consumption; the limit of $\mathrm{CO}^{2}$ emission is the important issue of current and future energy consumption; the traditional fossil energy will be exhausted eventually, and new energy is the important part of future energy consumption. Therefore, the safety of energy supply and consumption $\mathrm{C}_{\mathrm{IV}, 1}$, low emission energy consumption capacity $\mathrm{C}_{\mathrm{IV}, 2}$ and new energy development capacity $\mathrm{C}_{\mathrm{IV}, 3}$ are the constituent parts of energy consumption sustainability evaluation system.

Energy safety is a kind of matching state of energy supply and consumption. The interruption of external energy supply caused by sudden event will give rise to the interruption of energy consumption and affect normal social economic order. Therefore, the leading index of energy utilization evaluation in the field of energy safety is energy self-sufficiency. In the second place, the traditional fossil energy is also the main energy motivation in medium or short term, the longer the time (equal to the ratio of storage and exploitation quantity of unit time) of continuous exploitation under existing energy demand, the higher the safety of this kind of energy. Therefore, the storageproduction ratio of traditional fossil energy is the long term index of energy safety.

With the depth and popularization of international cooperation for tackling climate change, the low emission is the basic requirement for future energy consumption. Under current technical condition of energy utilization, the gas fuel $\mathrm{CO}^{2}$ emission ratio is lower than that of solid and liquid fuel, and the gas consumption capacity can be used as one of the indexes of sustainable development of energy consumption, which can be described with region energy gasification rate or enterprise gasification energy consumption proportion.

Finally, the introduction intensity and capital input of region or enterprise energy policy, energy saving technology and energy saving new product related to energy consumption will also affect the sustainability of energy utilization, which can be described with proportion of nonfossil energy, capital input of new energy project under construction and new energy development, etc.

Merging the above four Level B evaluation systems, we will obtain "Energy - Economy - Environment and Development (3E\&D) evaluation index system" of energy efficiency evaluation, as shown in Table 1. Of which, the determination of weight will be given in next section.

\section{SYSTEM WEIGHT}

$3 \mathrm{E} \& \mathrm{D}$ evaluation system is an evaluation index system with multiple dimensions, multiple levels and multiple indexes. The basic way of achieving its comprehensive evaluation is to calculate the score of each index upwards level by level from the bottom level. For this, it is necessary to do 3 jobs: 1 . calculate the index of the bottom level; 2 . determine the rule for calculating the index level by level from bottom to up; 3 . divide the levels of Level A comprehensive index, namely determine the levels number and corresponding redundancy value of comprehensive evaluation.

At present, many analytical technologies and methods of constructing comprehensive evaluation index have been developed, such as analytic hierarchy process (AHP), principal component analysis (PCA), cluster analysis, etc. Based on the characteristics of index system constructed in this paper, PCA method and AHP method are employed during the evaluation from bottom to up, and then the determination of weight becomes the important link of these methods. In this paper, "pairwise comparison - 9-level scale" method is adopted to obtain the judgment matrix of Level B index, as shown in Fig. (2), and its composition is described as follows:

The main function of energy system is to supply energy motivation (energy supply), and its purpose is to guarantee the development of social economy. Therefore, compared with the goal of energy supply, the goal of economy is more important, or absolutely important, it should be 8 points. Secondly, the energy production must be carried out on the 
Table 1. The energy efficiency evaluation system (3E\&D).

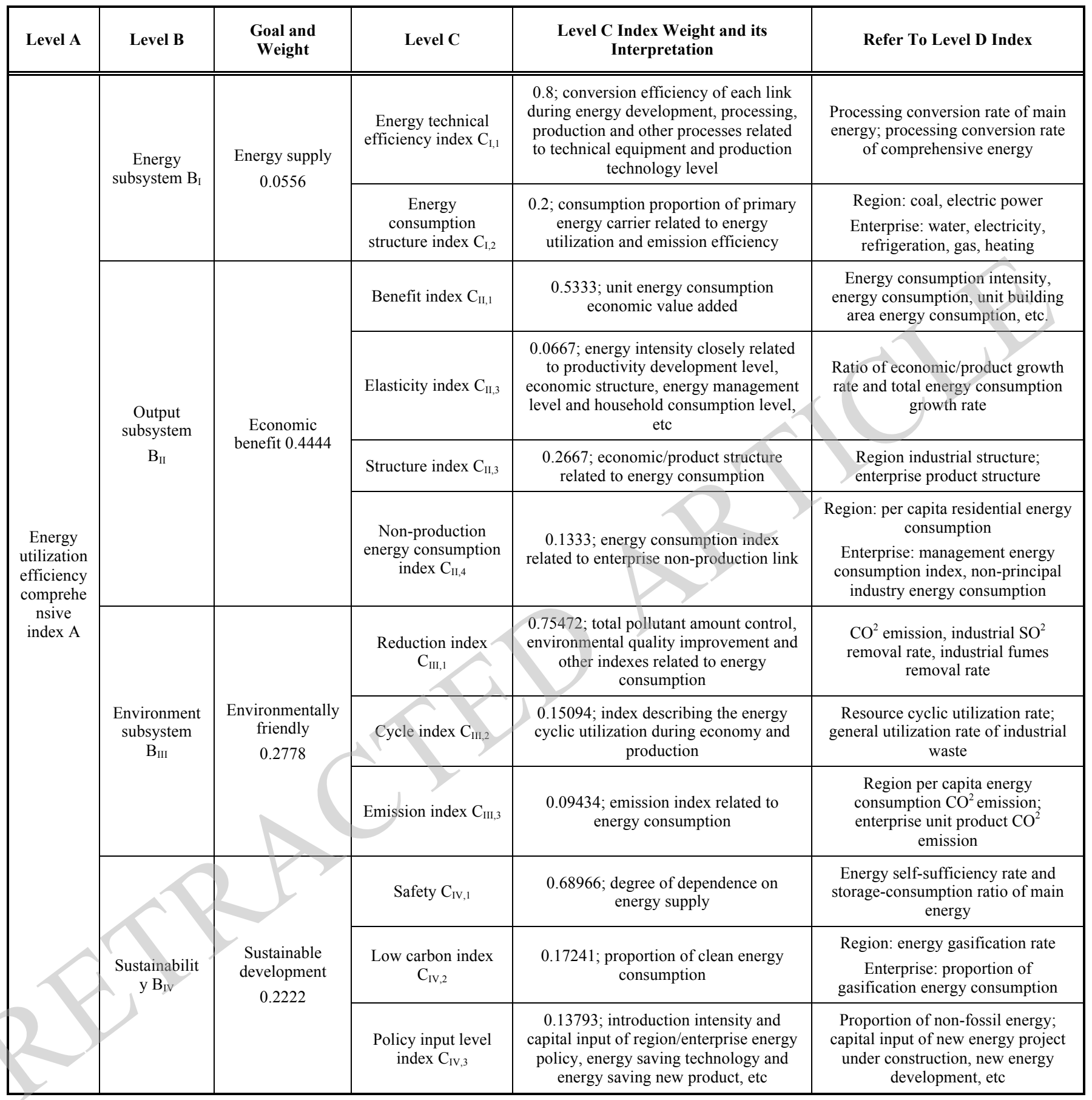

condition of not causing severe unrepairable environmental damage. Therefore, compared with energy supply, the environmental objective is quite important, it should be 5 points; similarly, the goal of sustainable development should be 4 points. From this, the first row of judgment matrix is obtained, and then the first line is obtained from the reciprocity of judgment matrix; finally, the whole judgment matrix can be obtained from the consistency. This is a consistent and reciprocal positive matrix, and the largest characteristic value of it is 4 , and the feature vector is $(1,8$, 5 , and 4). The weight of Level $\mathrm{C}$ index can be obtained with the same method. The weight and value of Level D index should be given with appropriate method according to application area. The weight of evaluation system is as shown in Table 2.

Table 2. The judgment matrix of the B subsystem.

\begin{tabular}{|c|c|c|c|c|c|}
\hline B & I & II & III & IV & Weight \\
\hline \hline I & 1 & 0.125 & 0.2 & 0.25 & 0.0556 \\
\hline II & 8 & 1 & 1.6 & 2 & 0.4444 \\
\hline III & 5 & 0.625 & 1 & 1.25 & 0.2778 \\
\hline IV & 4 & 0.5 & 0.8 & 1 & 0.2222 \\
\hline
\end{tabular}




\section{CONCLUSION}

3E\&D energy efficiency comprehensive evaluation index system presented in this paper scientifically divides the energy efficiency into four subsystems, i.e. energy subsystem, output subsystem, environment subsystem and sustainability subsystem, and systematically reflects region, industry or enterprise energy utilization efficiency. This index system can be applied to the evaluation of energy efficiency and the forecast of energy consumption, and also can be used for guiding energy saving and emission reduction, with wide applicability at macro and micro level.

\section{CONFLICT OF INTEREST}

The authors confirm that this article content has no conflict of interest.

\section{ACKNOWLEDGEMENTS}

Declared none.

\section{REFERENCES}

[1] $\mathrm{Wu}, \mathrm{Q}$.; Wu, C. DEA-based energy efficiency evaluation model research. Manag. Sci., 2009, 2, 103-112.

[2] Feng, D. China region energy economics and environmental regulation. Lanzhou: Lanzhou University, 2007.

[3] Tong, Q.; Bai, Q.; Liu, B.; Lu, Y. The application of MARKAL model in beijing mid-long-term energy development research. Energy of China, 2004, 6, 37-41.

[4] Larson, E.D.; Wu Z.; DeLaquil, P.; Chen, W. Future implications of China's energy-technology choices. Energy Policy, 2003, 12, 11891204.
[5] Wang, C.; Chen, J.; Zou, J. The Impact of CGE model - based CO2 reduction on chinese economy. J. Tsinghua Univ., Sci. Technol., 2005, 12, 39-42.

[6] Huang, Y.; Guo, Z.; Zhang, T. Quantitatively analyze the feasibility of implementing energy environment tax policy in china with cge model. Urban Environ. Urban Ecol., 2005, 2, 21-23.

[7] Jorgenson, D.W.; Wilcoxen, P.J. Intertemporal general equilibrium modeling of U.S. environmental regulation. J. Policy Model., 1990, 12(4), 715-744.

[8] Xie, J.; Saltzman, S. An environmental computable general equilibrium approach for developing countries. J. Policy Model., 2000, 22(4), 453-489.

[9] Zheng, Y.; Fan, M. China CGE model and its policy analysis. Beijing: Social Literature Press, 1999.

[10] Carpos, P.; Karadeloglou P.; Mentzas G.N. Energy policy extensions of KLE based macroeconomic models. J. Policy Model., 1989, 11(4), 507- 530

[11] Zheng, Y.; Fan, M. CGE Model and Policy Analysis in China. Beijing: Social Science Literature Press, 1999.

[12] Jiang, K.; Morita, T.; Masui, T.; Matsuoka, Y. Global long-term GHG mitigation emission scenarios based on AIM. Environment Economics and Policy Studies, 2000, 3, 239-254.

[13] Wang L. Zhejiang Energy - Economy - Environment harmonious development research - based on the view of energy environment fairness. Hangzhou: Zhejiang Sci-Tech Univ., 2010.

[14] He, J.; Zhang, A.; Shang, C. NET EnergySystem model applied to the evaluation of greenhouse gas reduction. J. Tsinghua Univ. Sci. Technol., 1996, 36, 68-73.

[15] Zhang, A.; Zheng, H.; He, J. Economy, Energy, Environment (3E) model suitable for the actual condition of china. Journal of Tsinghua University, Science and Technology, 2002, 12, 1616-1620.

[16] Sun, N. Energy Consumption Evaluation and Optimization Decision Research of Oilfield Enterprise. East China: China University of Petroleum, 2008.

[17] He, S.; Huang, D. The research on zhejiang sustainable development energy index. Energy Eng., 2007, 2, 1-6. 